\title{
SANTA CRUZ DO SUL, ARQUITETURA E URBANISMO
}

\author{
Vanessa Rachor ${ }^{1}$ \\ Doris Maria Machado de Bittencourt ${ }^{2}$ \\ Milton Roberto Keller ${ }^{2}$
}

\section{RESUMO}

Este trabalho faz parte do Projeto de Pesquisa "Santa Cruz do Sul Arquitetura e Urbanismo", coordenado pela professora Dra. Doris Maria M. de Bittencourt, com a participação do professor Ms. Milton Keller. A arquitetura em Santa Cruz do Sul encontra-se em constante transformação, considerando-se desde a imigração até os dias atuais. Mudanças sociais e econômicas promovem sua evolução formal e estética, evidenciando-se uma história cultural. O objetivo é pesquisar e analisar a arquitetura erudita da imigração alemã na área central da cidade. Considera-se que o Movimento Moderno na arquitetura de Santa Cruz do Sul, passa por um processo evolutivo que, nos anos 30, aproximadamente, sofre influência da Nova Objetividade (Sachlichkeit), trazida pelos imigrantes alemães, evoluindo até o Movimento Moderno, influenciado pela arquitetura norte-americana e europeia. $\mathrm{O}$ método de pesquisa seleciona quatro prédios que fazem parte de uma lista maior, por sua vez, estes quatro prédios são representativos da arquitetura modernista em Santa Cruz do Sul. Como resultado, a pesquisa foi divulgada no $\mathrm{XX}^{\mathrm{o}}$ Salão de Iniciação Científica da UNISC. A partir dos estudos, conclui-se que a arquitetura em Santa Cruz do Sul, passa por um processo com influências alemã e luso-brasileira até os anos 30, aproximadamente, quando se consolida a influência da Sachlichkeit e do Movimento Moderno.

Palavras-chave: Arquitetura. Patrimônio Arquitetônico. Santa Cruz do Sul.

\begin{abstract}
This study is part of the Research Project "Santa Cruz do Sul Arquitetura e Urbanismo", coordinated by Prof. Dra. Doris Maria M. de Bittencourt, with the participation of Prof. Me. Milton Keller. The architecture in Santa Cruz do Sul is constantly changing, considering from immigration to present days. Social and economic changes promote its formal and aesthetic evolution, highlighting a cultural history. The aim of this study is to research and analyze over the classical architecture of German immigration, in the central area of Santa Cruz do Sul. It is considered that the Modern Movement in the city's architecture is going through an evolutionary process, that in the 30s, approximately, was influenced by the New Objectivity (in German: Neue Sachlichkeit), brought by German immigrants, evolving into the Modern Movement, influenced by North-American and European architecture. The research method selects four buildings that are part of a larger list; these four buildings are representative of the modernist architecture in Santa Cruz do Sul. As a result, this research was disclosed at the $X^{\circ}$ Salão de Iniciação Científica da UNISC. From the studies, it was concluded that the architecture in Santa Cruz do Sul, went through a process with German and Portuguese/Brazilian influences until the 30s, when it was consolidated the influence of Sachlichkeit and the Modern Movement.
\end{abstract}

Keywords: Architecture. Architectural heritage. Santa Cruz do Sul.

\footnotetext{
1 Aluna do Curso de Arquitetura e Urbanismo da Universidade de Santa Cruz do Sul. <vanessarachor@hotmail.com>

${ }^{2}$ Professores do Departamento de Engenharia, Arquitetura e Ciências Agrárias na Universidade de Santa Cruz do Sul.<dbitt@terra.com.br><milton@arquiteturacontemporanea.com.br>
} 


\section{INTRODUÇÃO}

Ao analisarmos as transformações sociais de um determinado local, percebe-se uma metamorfose de diversos gêneros. À medida que a cidade cresce, as transformações sociais e econômicas podem revelar uma história arquitetônica e urbana com múltiplos significados.

No caso de Santa Cruz do Sul, a partir do século XIX, seu cenário evolui formal e esteticamente, exibindo mudanças de valores, usos e hábitos. Considera-se que, no que se refere à arquitetura erudita, existem influências luso-brasileira e alemã que se expressam formalmente até, aproximadamente, os anos 30. Nesse período a evolução arquitetônica mostra a influência do movimento europeu Sachlichkeit trazido pelos imigrantes de origem alemã.

A proposta deste trabalho é a análise e documentação da arquitetura erudita da imigração alemã na área central da cidade, considerando o processo de evolução da arquitetura, que ao abandonar o ecletismo dos anos 30, evolui em direção a uma simplificação formal, que emprega linhas limpas e despojadas, influenciada pelo movimento arquitetônico europeu Nova Objetividade ou Sachlichkeit, trazido pelos imigrantes alemães.

A influência alemã sofre uma severa interrupção com a criação do CONFEA-CREA, em 1933, que dificulta aos imigrantes alemães a regularização do diploma e o direito de exercer a profissão.

Fazendo parte de um processo evolutivo, a arquitetura santa-cruzense absorve a influência da norte-americana, propagada pelos mestres europeus que se refugiam nos Estados Unidos, devido a problemas com o nazismo. A obra de Mies Van Der Rohe, Walter Gropius, Marcel Breuer e Frank Lloyd Wright e também do europeu Le Corbusier, influencia a arquitetura brasileira, e, obviamente, a santa-cruzense. Tal fato acentua-se após o término da II Guerra Mundial, quando os Estados Unidos passam a exercer uma grande influência na vida dos brasileiros.

A arquitetura modernista em Santa Cruz do Sul, em conformidade com o Movimento Moderno, se caracteriza pela horizontalidade, por buscar uma organização de planos, valorizar a autenticidade dos materiais e primar pela funcionalidade. Os quatro objetos da pesquisa que fazem parte deste artigo enquadram-se nesta caracterização. Como um todo, o Projeto de Pesquisa, "Santa Cruz do Sul, Arquitetura e Urbanismo" possui uma lista de objetos arquitetônicos mais extensa. 
Assim, aborda-se a produção de arquitetos imigrantes e brasileiros, podendo-se relacionar as tipologias residências às conquistas da mulher, observando a dupla influência luso-brasileira e alemã.

Para cada prédio foi estudado, desde a história de vida de seus proprietários até o sistema construtivo e situação atual, priorizando a valorização do Patrimônio Arquitetônico e Urbanístico local.

\section{FUNDAMENTAÇÃO TEÓRICA}

A Colônia Santa Cruz foi fundada em 19 de dezembro de 1849, quando chegaram os primeiros imigrantes na Picada Velha. O período entre 1849-1872 denomina-se "fase colonial" da Colônia Santa Cruz. Em 1872, a Colônia foi extinta. Os primeiros imigrantes que chegaram em 1849 foram Augusto Wutke, Frederico Thiestze, Augusto Rafler, Augusto Mandler, João Gottlobo Pohl e Augusto Arnold (MARTIN, 1999).

A instalação da colônia foi iniciada por trabalhos de medição das quadras, em 1854. Desconsiderando a geografia local, a demarcação dos lotes foi feita por meio de quarteirões, onde o traçado era como um tabuleiro de xadrez. Cada quadra foi compreendia 22 lotes, sendo nomeada com letras de A a U. Após foram acrescentadas as quadras nomeadas até Y. Primeiramente, Santa Cruz foi designada como Freguesia (1859), após foi designada Vila (1877) e elevada à condição de município em 28 de setembro de 1878 (MARTIN, 1999).

Foi aberto o traçado das primeiras ruas e estabelecidas as primeiras quadras da Povoação. Ficou marcado o local da Igreja Católica, dos edifícios públicos, das praças e das chácaras. O local para a Igreja Católica foi o mesmo ainda hoje ocupado pela Catedral, mais precisamente o jardim da parte da fronteira. (MARTIN, 1999, p. 25). 
Figura 1 - Planta da Freguesia de Santa Cruz do Sul (1870)

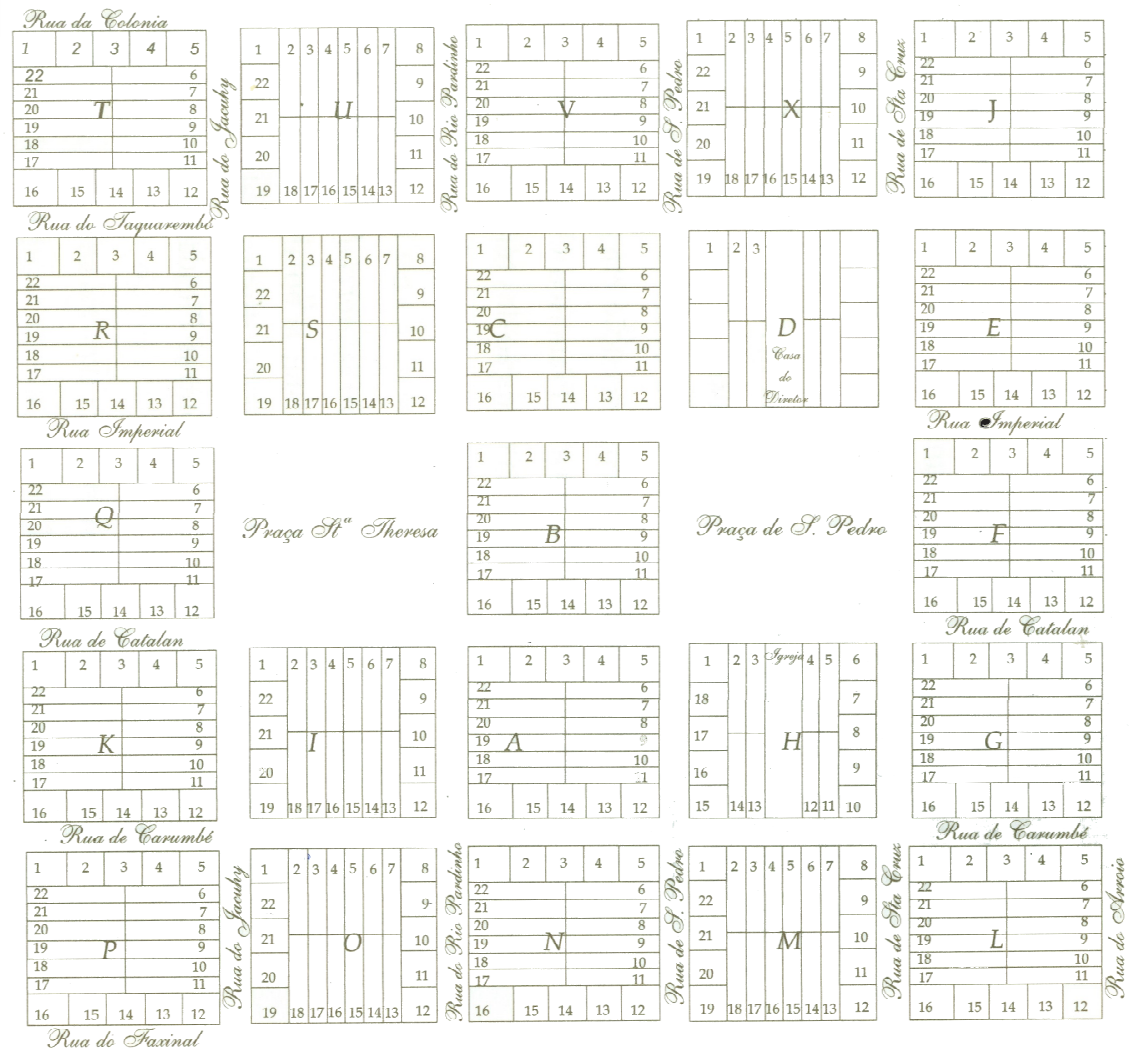

Fonte: Livro Recortes do Passado de Santa Cruz do Sul, de Hardy Elmiro Martin

De acordo com Weimer (1998), a criação da arquitetura modernista se deu a partir do espaço da produção arquitetônica que a antecipou, sendo de fundamental importância para o seu surgimento, a arquitetura eclética. Alguns estudos afirmam que o Movimento Moderno em Santa Cruz do Sul teve a influência da arquitetura erudita da imigração alemã, outras teorias apontam que o mesmo teve a influência do Movimento Moderno vindo da Europa com Le Corbusier - como também, dos Estados Unidos - com Mies Van der Rohe. Movimento este, trazido à região por arquitetos como Ary Hugo Seidl, Karl Budiner e Arlindo Kothe, tendo como principais características o uso do ângulo reto, o telhado borboleta, a continuidade espacial, entre outros.

O austríaco Eugênio Steinhof exerceu influências sobre o arquiteto Ary Seidl, era seu professor. Elas ficam evidentes no conjunto de residências projetadas por ele em Santa Cruz do Sul. A influência da arquitetura norte-americana dos anos 50 é expressa nitidamente ao observar o conjunto arquitetônico do arquiteto. 
Os edifícios residenciais com amplas coberturas de telhados aparentes, com generosos beirais desenhados pelo americano Frank Lloyd Wright bem como as experiências de Marcel Breuer nas unidades habitacionais implantadas em vários locais dos Estados Unidos, inclusive dentro dos Jardins do Museu de Arte Moderna de Nova York, em 1949, foram importantes para a arquitetura de Ary Seidl. As propostas de Walter Gropius e Mies Van der Rohe, que estiveram à frente das vanguardas ortodoxas a um racionalismo essencial, reforçado pelas ideias funcionais do professor Steinhof, bem como as experiências norte-americanas já mencionadas, produzem um efeito marcante no resultado formal desenvolvido pelo arquiteto em Santa Cruz do Sul. (HELFER, 2003, p. 167)

\section{MATERIAIS E MÉTODOS}

O plano de trabalho do bolsista foi organizado e solicitado pela professora. Ele é uma parte do projeto e atua como forma de envolvimento do aluno na pesquisa.

O projeto de pesquisa foi desenvolvido na área central da cidade de Santa Cruz do Sul, onde foi abordado o estudo de sua formação, acompanhando seu desenvolvimento e movimentos de imigração no local.

Desta forma, a escolha dos quatro objetos de pesquisa parte de um levantamento de prédios existentes em Santa Cruz do Sul, com o objetivo de formar uma Lista dos Prédios da cidade que devem ser tombados por órgãos do Patrimônio Histórico e Arquitetônico. O levantamento denomina-se "Inventário do Patrimônio Arquitetônico de Santa Cruz do Sul", elaborado, em 2003, pelos professores arquitetos Milton Keller, Ronaldo Wink, Heleniza Campos, Luis Schneider, Rosane Backes e Mara Kramer.

Desta forma, para este trabalho foram realizados levantamentos fotográficos e entrevistas com os proprietários, que serviram de embasamento para a análise.

Os procedimentos da pesquisa constam de revisão bibliográfica de títulos selecionados, que auxiliam na elaboração dos textos e seleção dos prédios a serem incluídos no trabalho.

Com base na pesquisa de alguns arquitetos, como na Tese de Doutorado de Felipe Helfer, abrangeu-se o estudo sobre o arquiteto Ary Hugo Seidl, que deixou um grande legado ao município de Santa Cruz do Sul, sendo este o arquiteto responsável pelas quatro obras residenciais abordadas na pesquisa. A isto soma-se a entrevista realizada com seu filho adotivo José Arnold realizada pelos professores Bittencourt e Keller em Gramado.

A partir da seleção de prédios, procurou-se realizar entrevistas com os proprietários das edificações que, por sua vez, relataram toda a história da residência, - servindo de embasamento para os textos do projeto - que, por muitas vezes, revela os estilos e práticas utilizadas pelos arquitetos. 
Juntamente com os relatos, foram feitos levantamentos fotográficos que tiveram fundamental importância para a compreensão dos projetos. No trabalho, os textos são complementados, além de imagens, pelas plantas originais das edificações, facilitando ainda mais o entendimento do mesmo.

\section{RESULTADOS}

A primeira obra avaliada foi a Casa Kern, propriedade de Astrid Mitch Baunhardt, a segunda foi a Casa Sohnle - proprietário não divulgado -, a terceira foi a Casa Hennes, de Denise Lopes, e a quarta foi a Casa Pranke - proprietário não divulgado. Todas as residências estudadas ficam situadas na área central de Santa Cruz do Sul - RS.

\subsection{Casa Kern}

\subsubsection{Levantamento físico-visual}

A partir dos levantamentos fotográficos pesquisados no CEDOC-UNISC e daqueles realizados pela equipe de pesquisa, incluiu-se as plantas-baixas originais fornecidas pelos proprietários e ou pesquisadas na Prefeitura Municipal de Santa Cruz do Sul, sendo assim possível a compreensão dos sistemas construtivos, bem como uma melhor leitura do projeto arquitetônico.

\section{Figura 2 - Casa Kern}

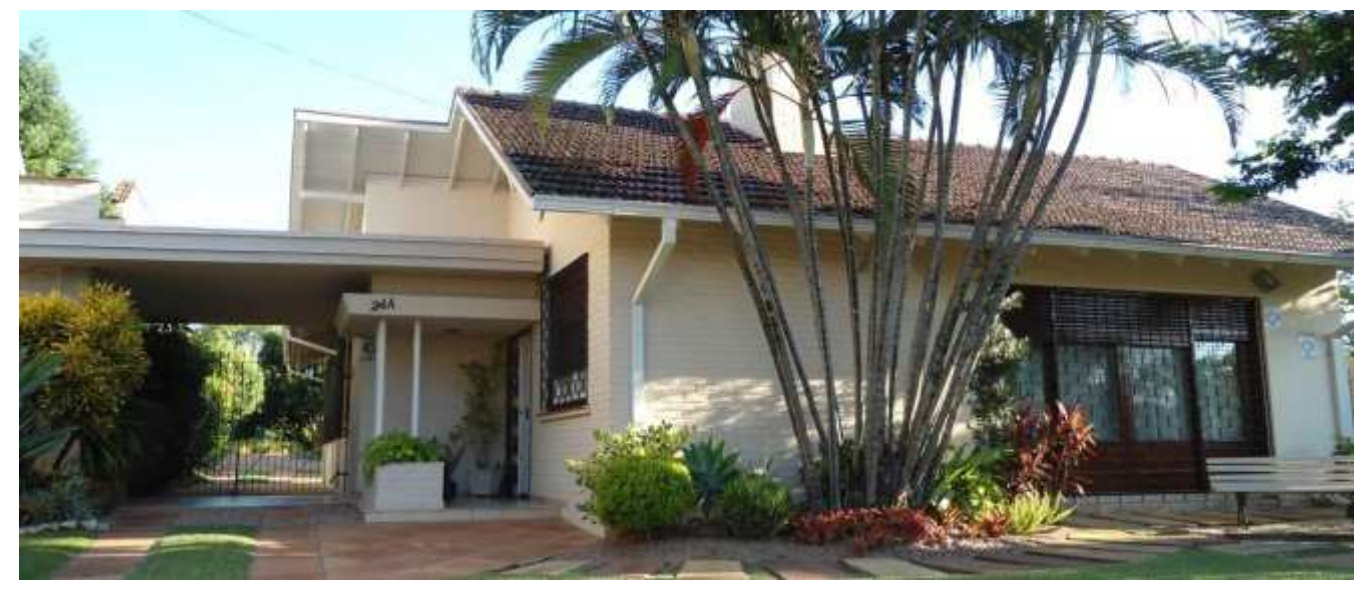

Fonte: equipe de pesquisa 
Figura 3 - Planta baixa Casa Kern

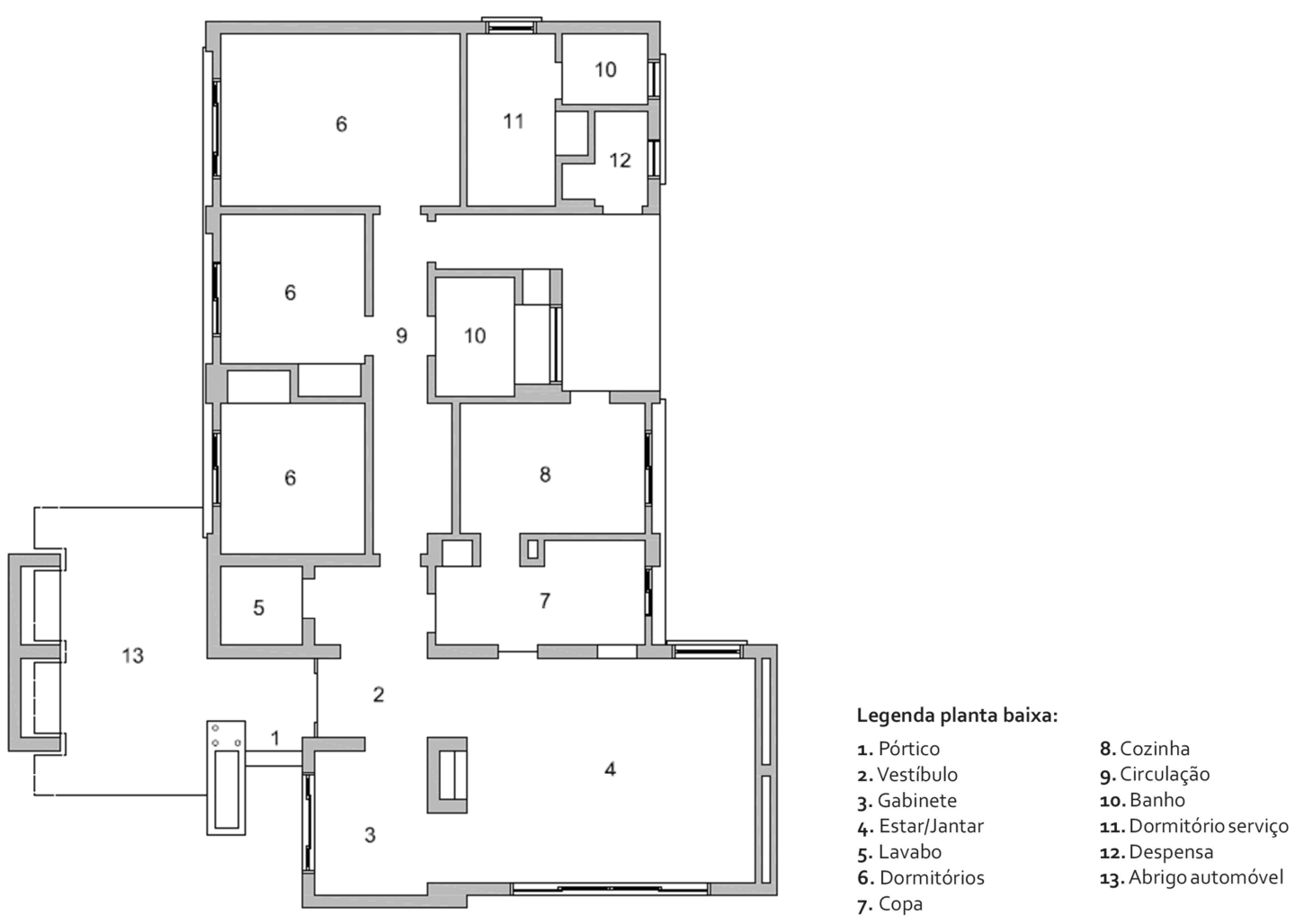

Fonte: equipe de pesquisa.

Figura 4 - Fachada principal Casa Kern

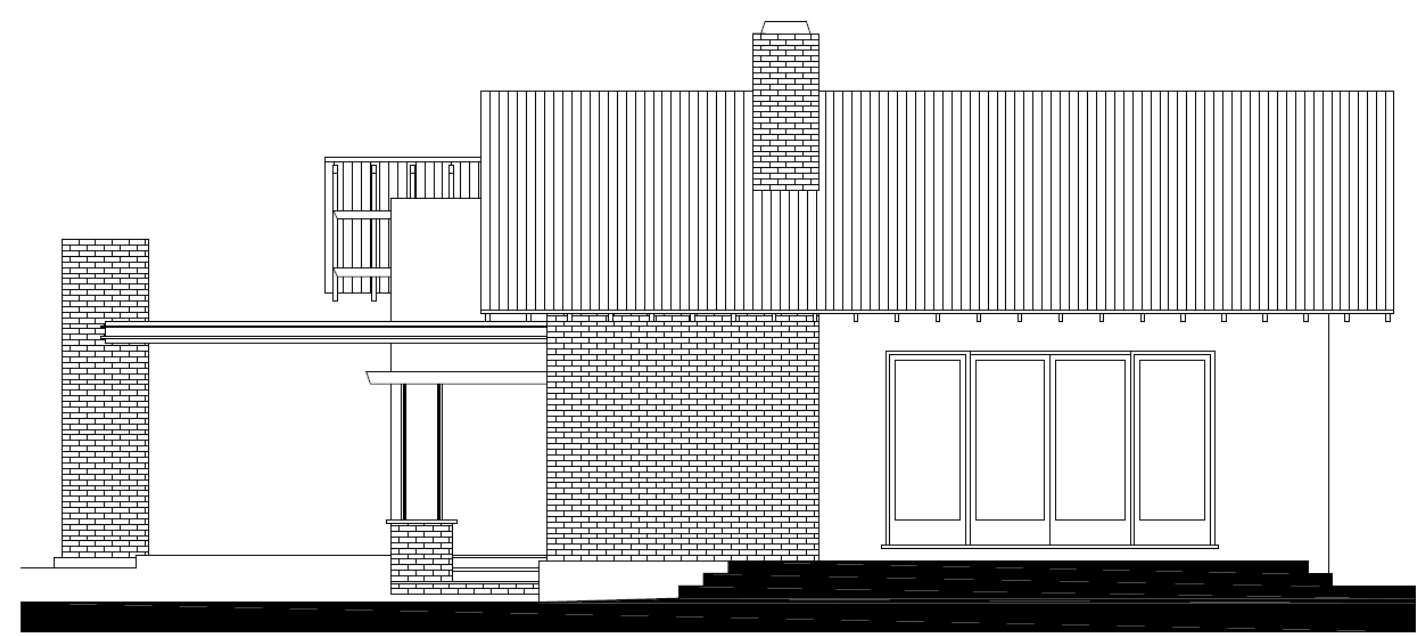

Fonte: equipe de pesquisa. 


\subsubsection{Fonte de pesquisa}

\subsubsection{Entrevista com a proprietária Astrid Mitch Baunhardt}

O arquiteto Ary Hugo Seidl elaborou a casa para um casal e dois filhos, mas logo o casal teve uma surpresa, tiveram mais duas filhas gêmeas. Assim, a casa teve de ser adaptada para uma família com quatro filhos.

$\mathrm{Na}$ casa, o arquiteto fez o uso da planta econômica, com a ideia de adaptá-la a um padrão de vida moderno, com uma arquitetura que se desenvolve de dentro para fora, sendo a fachada uma consequência do espaço interno.

Visando o conforto ambiental, fez-se o uso de paredes duplas com camada de ar nos ambientes voltados para oeste. Estas informações foram obtidas com a proprietária Astrid Mitch Baunhardt. O mobiliário da casa também foi paralelamente projetado pelo arquiteto.

Nas fachadas, como sua marca registrada, Ary Seidl usou o tijolo à vista, sempre valorizando a textura dos materiais. $\mathrm{O}$ destaque se dá na marquise do hall, que se apoia em finos pilotis metálicos, remetendo à casa de Walter Gropius, onde a marquise parece flutuar.

\subsection{Casa Sohnle}

\subsubsection{Levantamento físico-visual}

A partir dos levantamentos fotográficos e com o auxílio das plantas originais, foi possível a compreensão dos sistemas construtivos, bem como uma melhor leitura do projeto arquitetônico.

\section{Figura 5 - Fachada principal Casa Sohnle}

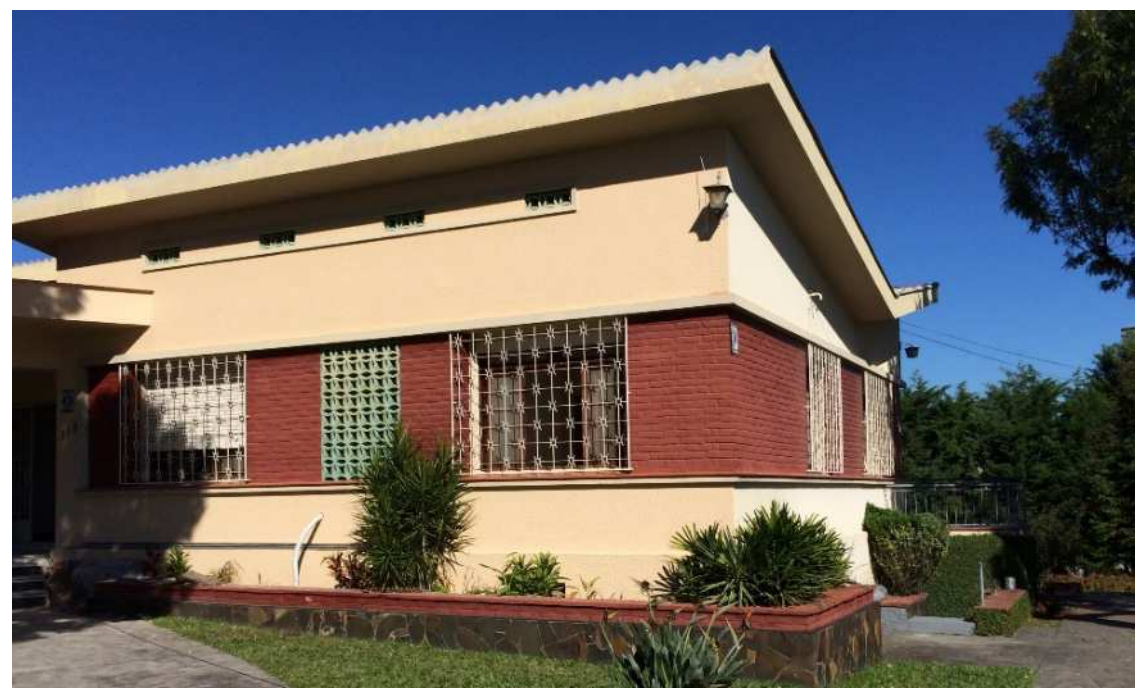

Fonte: equipe de pesquisa. 
Figura 6 - Planta baixa térreo Casa Sohnle

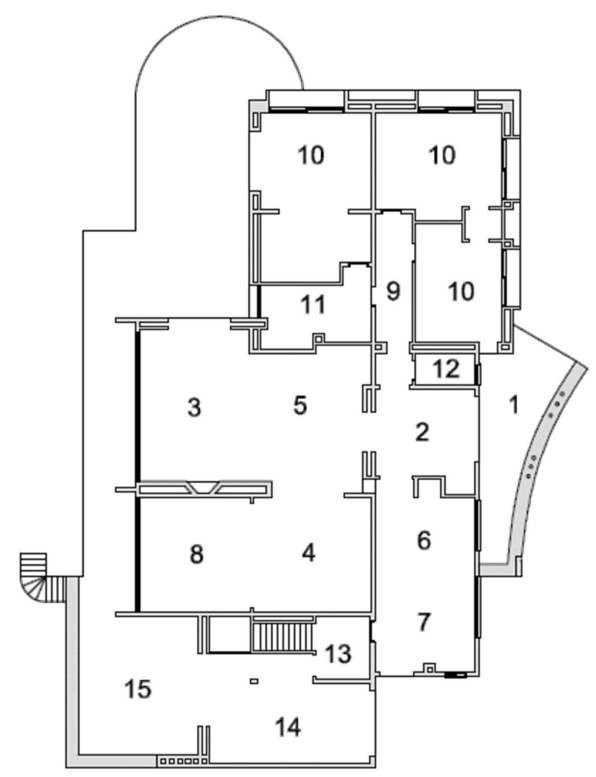

Figura 7 - Planta baixa porão

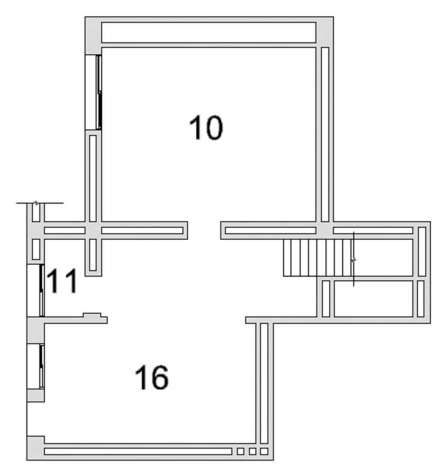

Legenda plantas baixas:

1. Pórtico

9. Circulação

2. Hall 10. Dormitórios

3. Sala de estar 11. Banhos

4. Sala de jantar 12. Lavabo

5. Biblioteca 13. Despensa

6. Copa 14. Garagem

7. Cozinha 15. Terraço

8. Jardim de inverno 16. Depósito

Fonte: proprietários da Casa Sohnle.

\section{Figura 8 - Fachada principal Casa Sohnle}

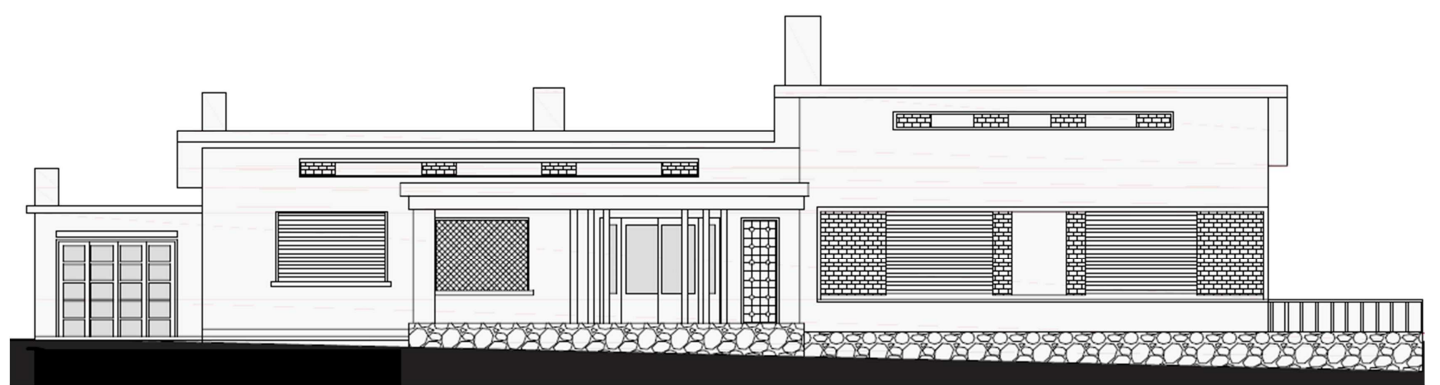

Fonte: proprietários da Casa Sohnle. 
4.2.2 Fonte de pesquisa

Para a elaboração dos textos, foi utilizado como principal referência a entrevista com a proprietária, a visita ao local, complementada com a Tese de Doutorado de Felipe Helfer Viagem Insólita.

A volumetria é composta por um volume único, onde é agregada uma elaborada marquise que fica apoiada em pilotis metálicos, inspirado em Mies Van der Rohe, marcando o acesso principal.

As funções de estar, jantar, biblioteca e jardim de inverno situam-se em um único ambiente, onde a separação dos mesmos se faz através do grande painel da lareira. Este foi revestido com pedras em tom ocre mescladas, formando desenhos abstratos.

Nas fachadas, fez-se o uso de barras horizontais enquadrando as janelas, elementos vazados para vedação e tijolo à vista. O grande destaque se dá para a cobertura, que teve como solução o telhado borboleta - influência que chegou a obra de grandes arquitetos brasileiros.

\subsection{Casa Hennes}

\subsubsection{Levantamento físico-visual}

A partir dos levantamentos fotográficos realizados pela equipe de pesquisa e com o auxílio de plantas originais, foi possível a compreensão dos sistemas construtivos, bem como uma melhor leitura do projeto arquitetônico. 
Figura 9 - Casa Hennes

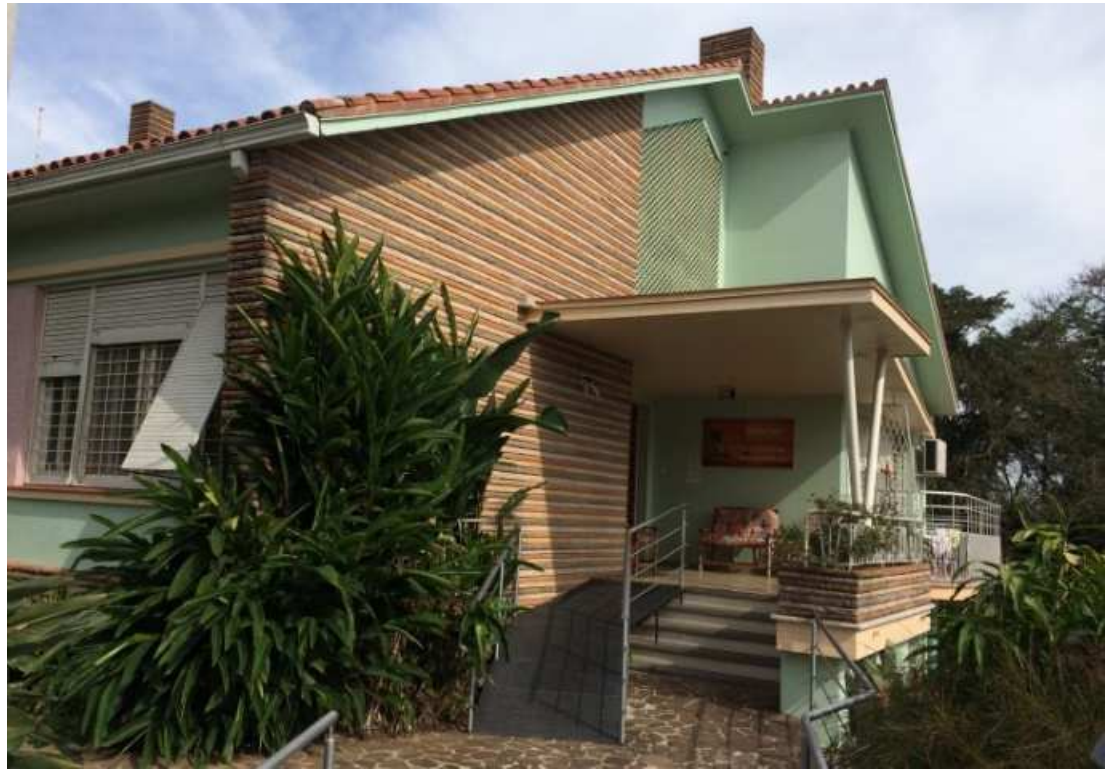

Fonte: equipe de pesquisa.

Figura 10 - Planta baixa térreo Casa Hennes

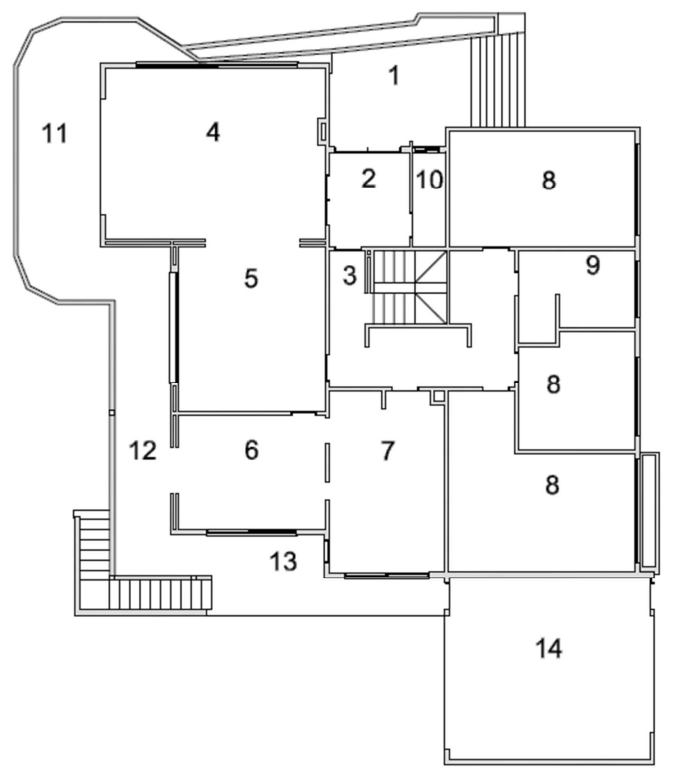

Legenda plantas baixas:

1. Pórtico 9. Cozinha

2. Terraço 10. Circulação

3. Hall 11. Banhos

4. Sala de jantar 12. Área

5. Sala de estar 13. Depósito

6. Jardim de inverno 14. Lavanderia

7. Dormitórios 15. Serviço

8. Copa 16. Escritório
Figura 11 - Planta baixa porão

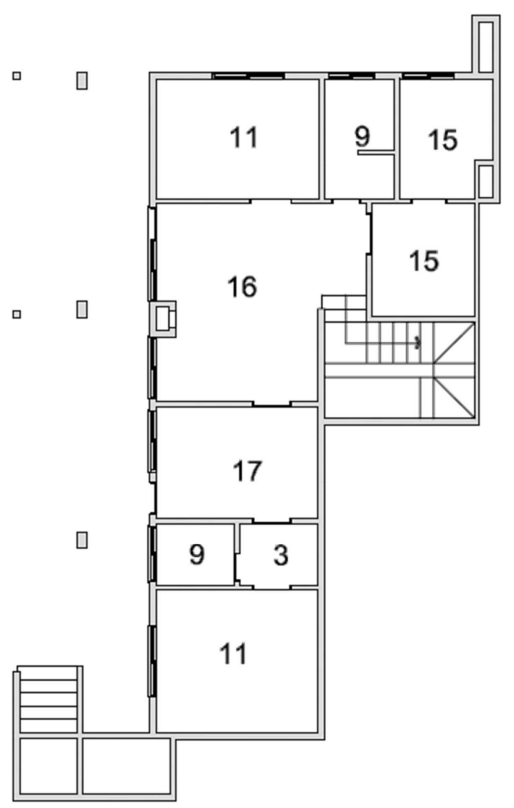

Fonte: proprietários da Casa Hennes. 


\section{Figura 12 - Fachada principal Casa Hennes}

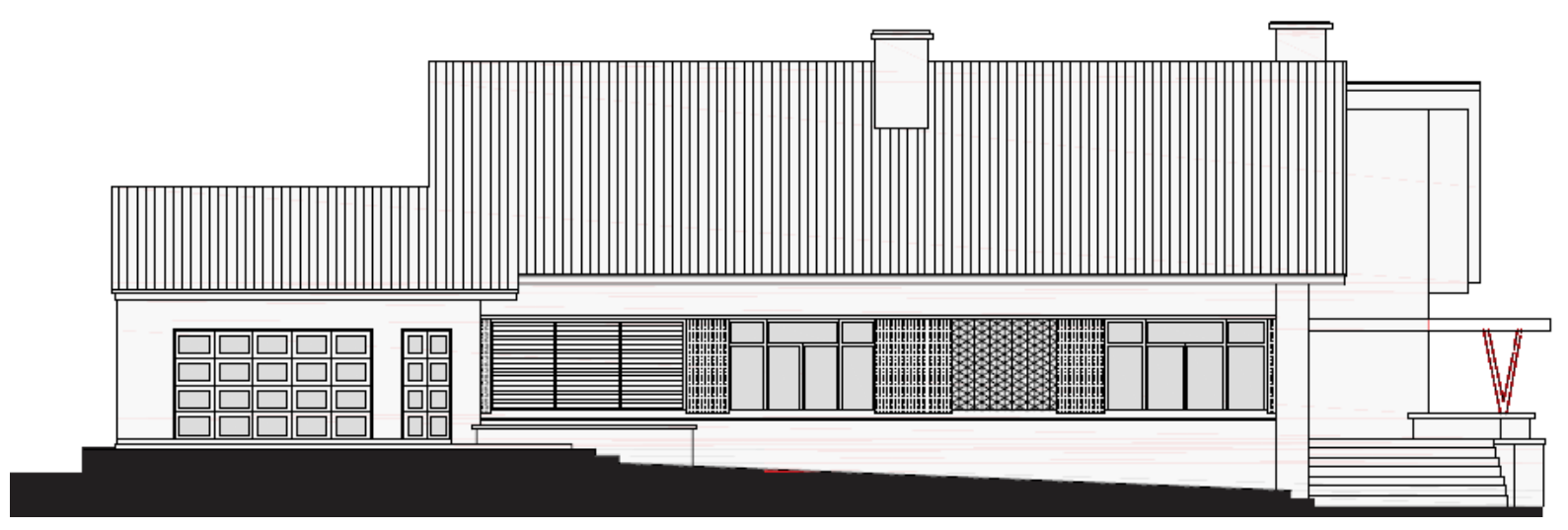

Fonte: proprietários da Casa Hennes.

\subsubsection{Fonte de pesquisa}

\subsubsection{Entrevista com a proprietária da Casa dos Idosos}

A solução compositiva é formada por dois grandes volumes agregados e levemente deslocados, mediados pelo plano horizontal do hall de entrada que se estende ao redor da residência como marquise.

A distribuição dos setores se faz a partir do hall. O estar, como proposta dos arquitetos modernistas, fica diretamente ligado ao jantar. A partir deste, tem-se acesso ao terraço.

O terraço dá acesso a um nível que seria um "subsolo", que compreende além da churrasqueira, um grande jardim nos fundos da casa.

Destaca-se o uso das janelas em fita, emolduradas por duas lajes - a do piso e a da marquise - como nos projetos de Mies Van der Rohe e Oscar Niemeyer.

A marquise de entrada assume maior importância neste projeto, com seus pilotis metálicos em V. 


\subsection{Casa Pranke}

\subsubsection{Levantamento físico-visual}

A partir dos levantamentos fotográficos e com o auxílio de plantas originais, foi possível a compreensão dos sistemas construtivos, bem como uma melhor leitura do projeto arquitetônico.

Figura 13 - Casa Pranke

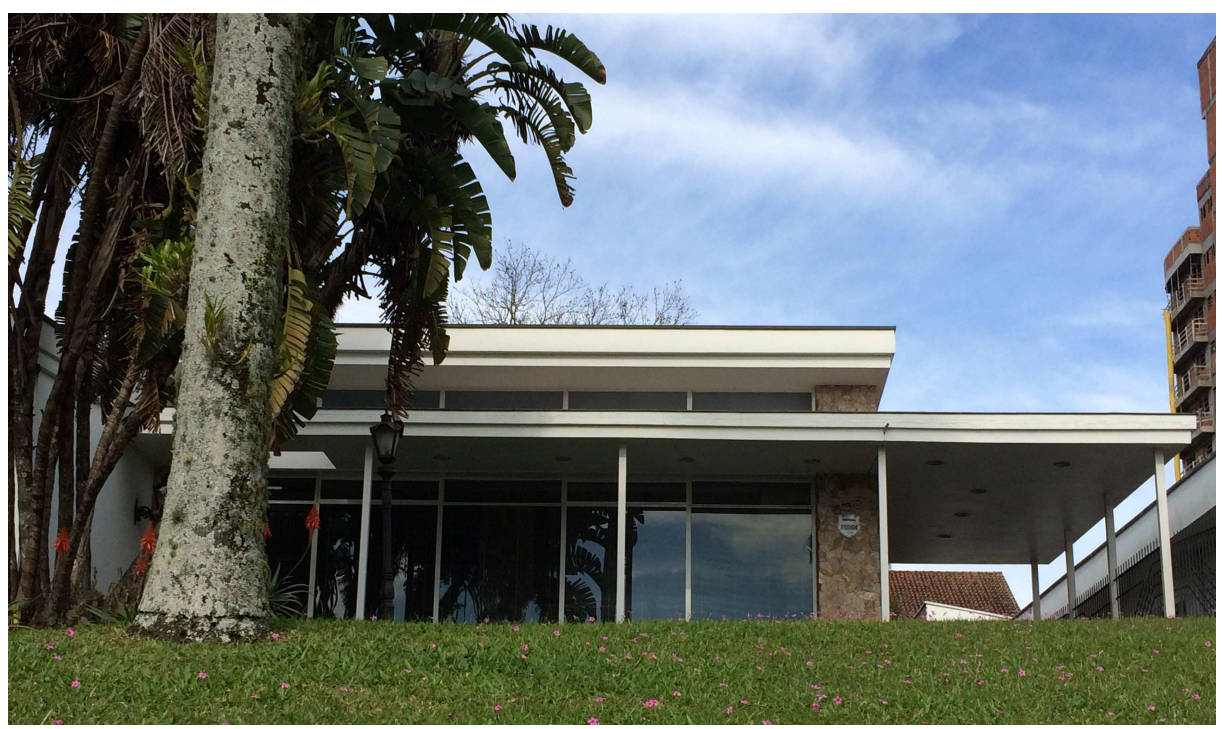

Fonte: equipe de pesquisa.

Figura 14 - Planta baixa Casa Pranke

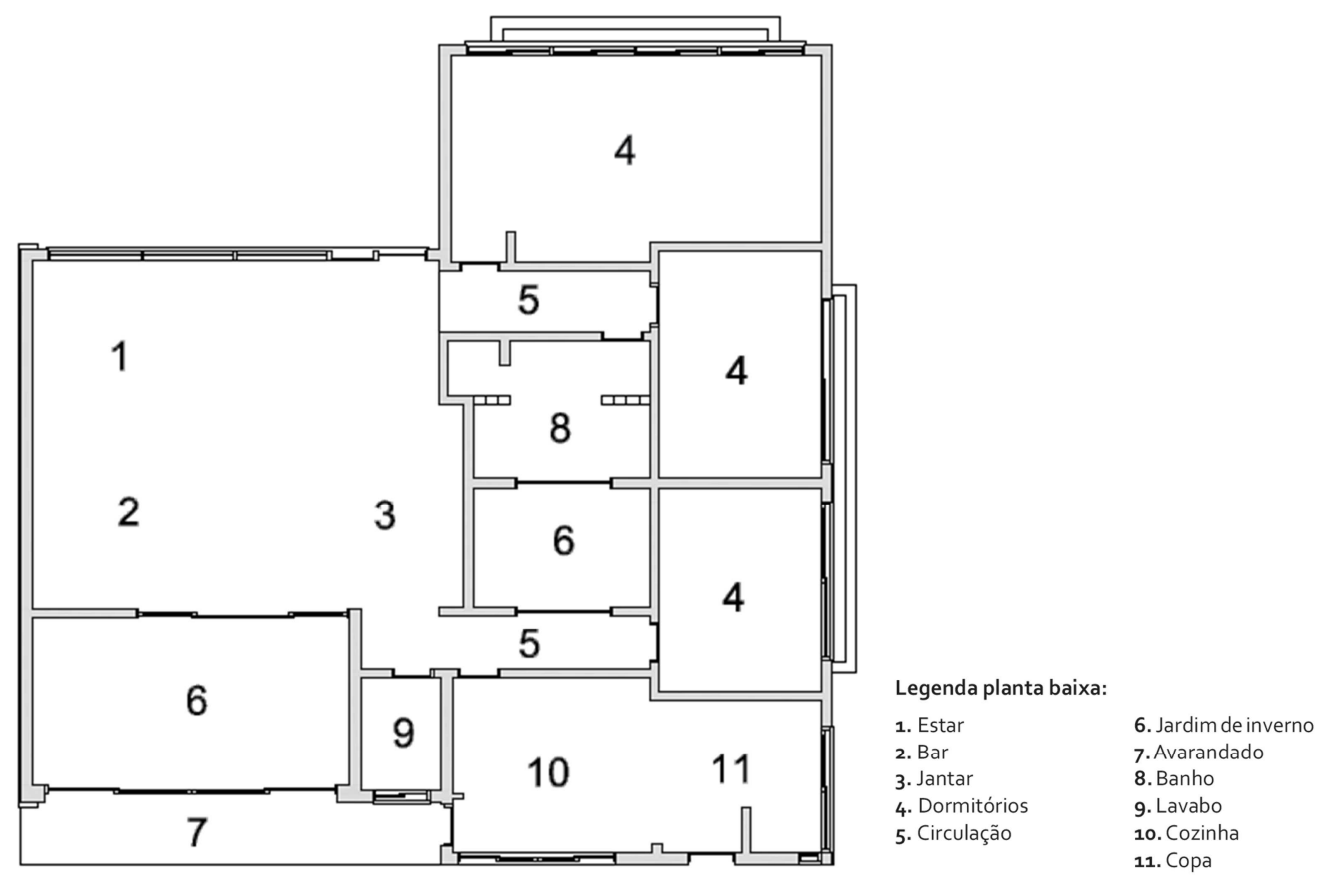

Fonte: equipe de pesquisa. 
Figura 15 - Fachada principal Casa Pranke

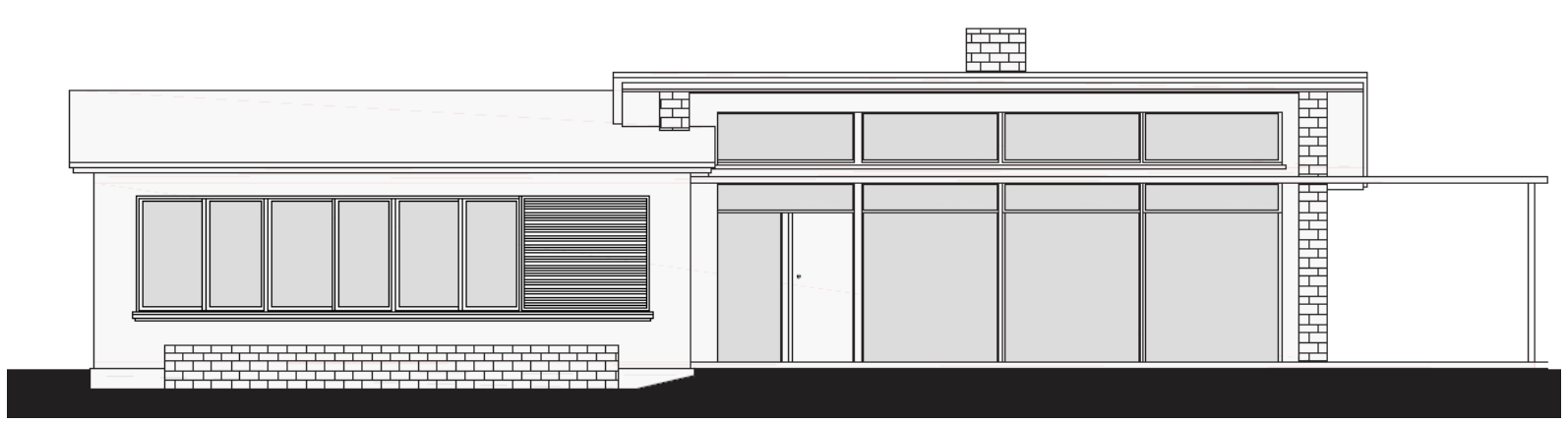

Fonte: equipe de pesquisa.

\subsubsection{Fonte de pesquisa}

\subsubsection{Entrevista com proprietária da Casa Pranke.}

A casa é organizada por planos perpendiculares em um terreno elevado, onde se destacam a horizontalidade, grandes panos de vidro e a integração entre o interior e exterior.

A marquise é um plano reto apoiada em pilotis de metal, articulando planos e volumes. Esta gera uma ampla varanda sem desníveis entre o interior e exterior.

O telhado com caimento mínimo fica totalmente oculto por uma grossa platibanda, que acentua a horizontalidade.

\subsection{Considerações parciais}

A tabela 1 reflete a situação atual das residências estudadas. É possível observar que todas elas encontram-se restauradas, todas com o devido cuidado para a preservação do modelo original, sendo que apenas duas das residências fizeram a substituição de elementos originais por novos. 
Tabela 1 - Situação atual das residências

\begin{tabular}{cccc}
\hline Residência & Grau de proteção & Estado de conservação & Uso atual \\
\hline Casa Kern & Não está protegida & Homogênea & Residencial \\
Casa Sohnle & Não está protegida & $\begin{array}{c}\text { Substituição de alguns elementos } \\
\text { originais por novos }\end{array}$ & Residencial \\
Casa Hennes & Não está protegida & $\begin{array}{c}\text { Substituição de alguns elementos } \\
\text { originais por novos }\end{array}$ & Clínica \\
& & Horiátrica \\
Casa Pranke & Não está protegida & Residencial & \\
\hline Fonte: tabela elaborada pelo autor a partir de informações obtidas durante a pesquisa.
\end{tabular}

\section{CONCLUSÕES}

A partir dos estudos realizados, pode-se afirmar que a cidade de Santa Cruz do Sul, em sua formação, tem nítida influência luso- brasileira e da imigração alemã no espaço urbano e também na arquitetura.

Após o final da II Guerra Mundial, a arquitetura modernista passa a influenciar a arquitetura brasileira. Os mestres do movimento moderno difundem sua influência a partir dos Estados Unidos. Fica explícita a influência de Frank Lloyd Wright, Walter Gropius, Marcel Breuer, Mies Van Der Rohe e Le Corbusier.

Em Santa Cruz do Sul, destaca-se o arquiteto Ary Hugo Seidl, formado pela escola de engenharia da UFRGS. Este teve grande influência de seu professor austríaco Eugênio Steinhof, o qual mantinha contato com arquitetos europeus.

Utilizando das inspirações europeias, o arquiteto produz um conjunto de casas, cerca de trinta obras construídas, nas quais predomina o telhado borboleta, a textura dos materiais aparente, janelas em banda e faixas horizontais em tijolo à vista. Cabe destacar também o desprezo por qualquer tipo de decoração e a busca pela racionalidade e funcionalidade herdada de seu mentor Eugenio Steinhof e Frank Lloyd Wright.

O grande destaque de seus projetos se dá na continuidade espacial entre o estar e o jardim, fazendo o uso de grandes panos de vidro com a intenção de possibilitar a visão do conforto e da modernidade da sociedade, rompendo assim a tradição dos casarões fechados. 
As casas de Ary adotam o estilo geométrico de Le Corbusier, jogando com volumes simples e engastados. Cria elaboradas marquises que irão evidenciar o acesso principal, estas sempre apoiadas em pilotis metálicos. Ressalta-se ainda o uso do telhado borboleta como solução de cobertura, influência que chegou a obra de grandes arquitetos brasileiros como Vilanova Artigas e Oscar Niemeyer e foi propagada pelo próprio Le Corbusier com sua Casa Errázuriz, no Chile.

Finalmente, pode-se afirmar que a arquitetura de Santa Cruz do Sul teve a influência da imigração alemã, mas paralelamente estava presente a cultura portuguesa. Particularmente os quatro projetos pesquisados, de nítida feição modernista, estão situados e fazem parte do processo evolutivo da arquitetura em Santa Cruz do Sul, que nos $30 \mathrm{com}$ sua arquitetura simplificada e sem decoração demonstrou a influência do movimento arquitetônico europeu Sachlichkeit e do Movimento Moderno da arquitetura, irradiado principalmente dos Estados Unidos. Sendo assim, o resultado final é a união destas diferentes culturas na arquitetura de Santa Cruz do Sul.

\section{REFERENCIAS}

HELFER, L. F. de L. Viagem insólita: a experiência da arquitetura moderna em Santa Cruz do Sul. Porto Alegre, 2003. 212 p. Dissertação e Mestrado em Arquitetura, Programa de Pesquisa e Pós-Graduação em Arquitetura, Universidade Federal do Rio Grande do Sul, 2003.

MARTIN, H. E. Organizado e atualizado por Olgário Paulo Vogt, Ana Carla Wunsch. Recortes do passado de Santa Cruz do Sul. Santa Cruz do Sul: EDUNISC, 1999.

WEIMER, G. Arquitetura erudita da imigração alemã no Rio Grande do Sul. São Paulo, 1989. Tese de Doutorado apresentada à USP, 1989.

Arquitetura erudita da imigração alemã no Rio Grande do Sul. Porto Alegre: EST Edições, 2004.

Arquitetura modernista em Porto Alegre: entre 1930 e 1945. Porto Alegre:

Unidade Editorial, 1998. 